\title{
The Influence of Reference Material for Sketching Strategies and Form Establishment at the Embodiment Design Level
}

\author{
Zainudin Siran'1, Shahriman Zainal Abidin², Rusmadiah Anwar ${ }^{3}$ \\ ${ }^{1}$ Centre for Immersive Digital Applications and Content (CISDEC), FCM, Multimedia University (MMU), 63100 Cyberjaya, Malaysia. \\ 2, ${ }^{3}$ Formgiving Design Research Group, Faculty of Art \& Design, Universiti Teknologi MARA, 40450 Shah Alam, Malaysia \\ zainudin.siran@mmu.edu.my, shahriman.z.a@uitm.edu.my, rusma935@uitm.edu.my \\ Tel: +603-83125942
}

\begin{abstract}
This paper purposely to understand the relationship between reference materials and form the embodiment process illustrated in the design drawing sketch. To review the respondent's design thinking characteristic and to surmise the scenario of the product development issue, a design protocol analysis put in place as a core method. Respondent behaviour throughout the design activities was recorded and analyzed through interaction design embodiment process. Analysing design activities and drawing sketch has produced some pattern which states the meaning of average design element, selected reference material, interaction behaviour, and the design process in a control situation.
\end{abstract}

Keywords: Interaction, Form Embodiment, Design Thinking Process, Design Elements

eISSN: 2398-4287@ 2020. The Authors. Published for AMER ABRA cE-Bsby e-International Publishing House, Ltd., UK. This is an open access article under the CC BYNC-ND license (http://creativecommons.org/licenses/by-nc-nd/4.0/). Peer-review under responsibility of AMER (Association of Malaysian Environment-Behaviour Researchers), ABRA (Association of Behavioural Researchers on Asians) and cE-Bs (Centre for Environment-Behaviour Studies), Faculty of Architecture, Planning \& Surveying, Universiti Teknologi MARA, Malaysia.

DOI: https://doi.org/10.21834/ebpj.v5iSl3.2546

\subsection{Introduction}

The issue of product usability strongly related to user knowledge, user experience, and product features. Problems become complex for specific type users such as disable or elderly people. According to Fukuda (2009), current appliances product features are not user-friendly for the elderly to use. Product features such as the integrated digital operating system and multi-function are inconvenient for them as they have vision and memory problems. As well as Gharib (2013) identified that small text, narrow screen size, less contrast background colour for the control panel, and inappropriate viewing angle demotivate them to use appliances product. In his research, he found some local Chinese elderly could not understand English text or symbol such as 'AL' and 'BELL.' All these issues required appropriate design study through form embodiment process for new product development (Anwar et al., 2015a). "The research required critical analysis (through interview, observation, experiments, and literature) to observe actual elderly behaviour while using the product" (Monö, 1997). Based on a rigorous research experiment, the data found will much accurate, close to the real situation, and help to find an effective solution. Design innovation changed the new product to be more competitive, enhance functionality and advance technology-driven (Prahalad et al., 2000). Three well-known models often as a scientific reference which is user-centred innovation, contextual based innovation and design-driven innovation (Brown et al., 1995). The design-driven innovation not much explored which stressing on user interaction with the product required to understand the design message from function and explore symbolic product value (Schön,1983) and (Brown et al.,1995).

eISSN: 2398-4287C 2020. The Authors. Published for AMER ABRA cE-Bsby e-International Publishing House, Ltd., UK. This is an open access article under the CC BYNC-ND license (http://creativecommons.org/licenses/by-nc-nd/4.0/). Peer-review under responsibility of AMER (Association of Malaysian Environment-Behaviour Researchers), ABRA (Association of Behavioural Researchers on Asians) and cE-Bs (Centre for Environment-Behaviour Studies), Faculty of Architecture, Planning \& Surveying, Universiti Teknologi MARA, Malaysia.

DOI: https://doi.org/10.21834/ebpj.v5iSI3.2546 


\subsection{Literature Review}

The interaction factor is influencing user behaviour to product usage. "The element of value is connecting the product and user" (Kumar et al., 2007). In this context, the connection is through interaction with product usability and user acceptance. The new product development (NPD) process involved product perception to analyze form embodiment and designer's thinking. The designer experience using products able to clarify the product function, design concept and product usage (Warell, 2008).

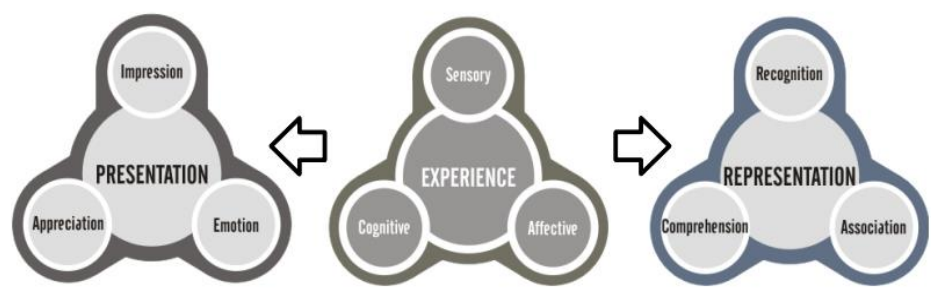

Fig. 1: Framework of perceptual product experience (PPE) (Warell, 2008)

The component of the PPE model consists of three major modes: experience, presentation and representation (Figure 1). It is performed in two dimensions which are presentation or representation category. While the element of experience comprises: i) Cognitive: means for product message, structure, function, identity, and purpose. The thinking aspect of designers, understanding, and experience of analyzing products, arranging information, visualize the idea and understand what they feel while designing the concept and design embodiment of the final decision. ii) Sensory: the initial impression and recognition of product existence and specific perceptual characteristics. Purposely to measure the form of development from the aspects of emotion and pleasurable. Involved designers experienced seeing how the elderly used a product. iii) Affective: product value-added and justification. About how the respondent expressed their feelings and emotions based on product usability. Interaction with reference material and selfexperience contribute a new value to the proposed design which meets the product usability issues. The specific meaning of submode from representation experience category is:

- Recognition (type): "What the product is" (function, use, purpose, maker).

- Comprehension (characteristics): "How the product is" (properties, performance, behavior, mode-of-use).

- Association (values): "What the product stands for" (origin, brand, heritage, user).

The specific meaning of sub-mode from presentation experience category is:

- Impression: a sensory experience, 'the best design idea,' different, paid attention, and early stage of experience.

- Appreciation: idea to form a new design.

- Emotion: 1) how the respondent evaluates the product. 2) How the respondent plans the design process toward decision making.

A product with a strong quality of sub-modes perceived as having a strong and clear identity. Through the application of the PPE framework, the researcher will clear the product purpose and product usability satisfaction (based on direct and non-interpretive experience which is the intuitions). This approach leads to understanding the respondent's design strategy (the design process) based on different knowledge disciplines.

While the Design embodiment is a Detailing a phase of form involves five steps (Pahl \& Beitz, 1996) that critically important to approach at the early stage of new product development. At this phase, required to consider various factors contribute to the product issues, where The Principle of problem-solving will be combined with the whole of the working principles of product function (Anwar et al., 2015b). Pahl \& Beitz, further added, through accumulated experiences and practices will enhance the embodiment process with the approach of basic rules simplicity, clarity and safety. While Hubka \& Eder (1982) underline three major components in the design process including the conceptual design, embodiment design and detail design.

\subsection{Methodology}

This research analysis used a perceptual product experience (PPE) model from Warell (2008) to clarify the elements of product perception. Through this model, the form embodiment process of Astro remote control (design subjects) will be studied as a qualitative assessment resulting in explicit dimensions for both sub-categories of presentation and representation. The analysis strategy to be achieved in this research is to identify the design, function, and product from experience from different respondent's backgrounds (Warell, 2008). The objective of this research is to analyze the message content of sketch drawing from the respondent, in the context of interaction with influence material (Anwar, 2016). Three research question which aligns with research objectives consist of: RQ1) which reference material mostly referred by the respondent to form a new design of remote control? Based on the PPE framework, this component related to recognition and association mode: function, maker, purpose, and use. RQ2) How the design outlook and the reason? Based on the PPE framework this component related to association mode: product usability, brand, and origin. RQ3) what is the factor they are considered for the design? Based on the PPE framework this component related to comprehension mode: performance, properties, behaviour, and mode of use. To answer all this question, a design experiment using a Design Protocol Analysis method (DPA) is approached (Anwar, 2016). 


\subsection{The Design Experiment}

In this design experiment, thirty final year students (Roscoe, 1975) participated from three different knowledge disciplines, engineering (ENG), interface design (ID), and industrial design (IDE). The design task is required to propose a new design of remote control for the Astro TV decoder to focus on the elderly user. The total time duration is twenty minutes for them to study and sketch the idea solution into the drawing template which consists of three abstraction levels: abstract, semi-concrete and concrete (Anwar, 2016). The experiment environment is equipped with three video cameras (different angle), four different influenced image panels, remote control sample and computer for internet searching, a drawing template and clock time (Anwar et al., 2016). The respondent's behaviour action during design activity will be recorded and analyzed for identification, contextualize and validate beside to study how they solve design problem influence from various reference material provided based on different knowledge domains. "The sketch drawing is the main medium for idea generation at the conceptual stage" (Siran et al., 2018) and "its link between design problem and concept solution" (McKim, 1980). This empirical investigation is exploring their intuitive development process, identify design elements, to perform product structure, and to clarify function mean analysis in form-giving (form creation) (Abidin et al., 2008; Anwar et al., 2015c). This empirical investigation is exploring their intuitive development process; identify design elements, to perform product structure, and to clarify function mean analysis in form-giving (Anwar et al., 2015c).

\subsection{Findings}

Figure 2 shows the design sketch drawing contains the form casing and the button function layout design proposed by all groups in the design experiment. Each group proposed a different concept of form structure design and the interface layout button design with a specific intention. Beside they spend different duration time on particular types of reference materials for design embodiment. For analysis, the data found is divided into two categories which are the eye interaction on reference materials (Table 1) and the sketch drawing of body casing form design (Figure 3, 4 and 5). Hence the data analysis will be gone through, based on the two categories, meant to clarify which reference material is focused at and the context that influences sketching strategies, to establish the embodiment design level of each group.

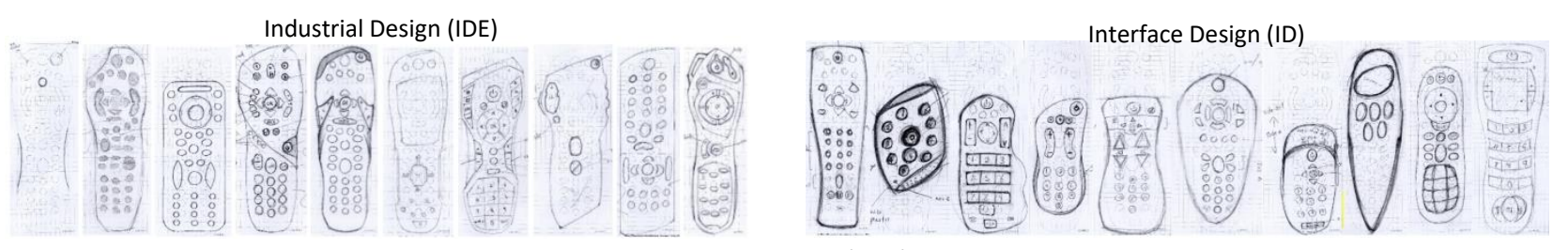

Engineering Design (ENG)

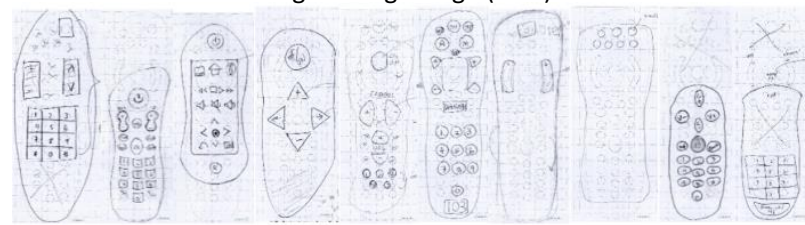

Fig. 2: Design abstraction of new Astro remote control from all groups

\subsection{Discussion}

\subsection{Analysis of Interaction with Reference Materials}

The data finding is analyzed to ensure which elements perceived with the meaning of PPE framework components recognition, comprehension, and associations. The analysis is focused on the interaction between reference material and the property of sketch drawing for the form development. The analysis result is answering the RQ1 of this research which related to reference material. Data from Table 1 shows respondents intensively refer internet $(29.5 \%)$ for the design process besides studying the button function and form design from the remote sample (28\%) and Panel $4(26.8 \%)$. Generally, all respondent from all group has less refer to Panel 1 and Panel 2. As well as the data analysis answers RQ3 regarding the fundamental issue of the task even though each group focus on a different factor. From the research data statistic, it clearly shows that respondent from both ID and ENG group is very concern on the major issue of elderly weakness as they begin the experiment with intensive research from the internet before starting the designing the remote control. Meanwhile respondent from the IDE group put their focus on aesthetic value as they actively interact with panel 4 and remote samples to begin the design task. They not even surf the internet to study elderly related matters as the main issue but directly proceed to sketch the idea solution into the drawing template. Generally, all respondents too much rely on current product specification, button function and elderly problems rather than introducing the innovative approach to remote control design suit to elderly weakness. Data from Table 1 shows some differences based on the frequency of respondent interaction and the total time spend. Most of the respondent starts observing all reference material briefly before starting the design task. Generally, they spend a long time on the internet searching, and then testing the remote sample (holding posture) and studying all buttons function 
(panel 4). Specifically, each group focuses on different reference material as an influence source for idea development. The engineering group (ENG) intensively interacts with the internet to search for extra information on elderly related matters (43\%), turn to study each button function through testing the remote sample (28\%) and panel $4(26.8 \%)$. The pattern of interaction quiet similar to the ID group, slightly lower percentage for each material reference. While different for Industrial Design (IDE) group where they begin the task with intensive interaction with Panel $4(45.6 \%)$ and remote sample (28.9) for them to understand all button functions before proceeding to draw the sketch. The data analysis also shows a big gap of respondent's acceptance of the reference materials to use for idea development. The open-source category of information (button function and internet) hit a high frequency of interaction (26\% $29 \%$ ). The panel 1 containing future innovative technology and similar lineup product (past and current model) received a low response (2\%-7.6\%). This means all respondents very much rely on current product specification, button function, and elderly problem scenario to redesign the Astro remote control.

Table 1: The time stamp of eye interaction on reference material form all group

\begin{tabular}{|c|c|c|c|c|c|c|c|c|c|}
\hline & $\begin{array}{c}\text { Panel } 1 \\
\text { (innovative } \\
\text { technology) }\end{array}$ & & & $\begin{array}{l}\text { Panel } 3 \\
\text { (current } \\
\text { model) }\end{array}$ & $\begin{array}{l}\text { Panel } 4 \\
\text { (Button } \\
\text { function) }\end{array}$ & $\begin{array}{c}\text { Remote } \\
\text { sample }\end{array}$ & Internet & Total & $\%$ \\
\hline IDE & 120 & & & 430 & 1560 & 990 & 100 & 3420 & $27.1 \%$ \\
\hline ENG & 110 & & & 220 & 1000 & 1230 & 2060 & 4800 & $38.0 \%$ \\
\hline ID & 100 & & & 320 & 830 & 1320 & 1570 & 4390 & $34.8 \%$ \\
\hline Total & 330 & & & 970 & 3390 & 3540 & 3730 & & \\
\hline$\%$ & $2.6 \%$ & & & $7.6 \%$ & $26.8 \%$ & $28 \%$ & $29.5 \%$ & & \\
\hline \multirow{2}{*}{\multicolumn{2}{|c|}{ Design Stages }} & \multicolumn{2}{|c|}{ ID } & \multicolumn{2}{|c|}{ ENG } & \multicolumn{2}{|c|}{ IDE } & \multicolumn{2}{|c|}{ Overall } \\
\hline & & Total & $\%$ & Total & $\%$ & Total & $\%$ & Total & $\%$ \\
\hline & Abstract & 2060 & 47.6 & 2080 & 43.3 & 2120 & 30.2 & 6260 & $38.8 \%$ \\
\hline Semi & Concrete & 1230 & 28.4 & 2000 & 41.6 & 2510 & 35.8 & 5740 & $35.6 \%$ \\
\hline & Concrete & 1030 & 23.8 & 720 & 15 & 2370 & 34 & 4120 & $25.6 \%$ \\
\hline & Total & 320 & 34.8 & 4800 & 38.0 & 7000 & 27.1 & & \\
\hline
\end{tabular}

\subsection{Analysis of Sketch Drawing of Form Development}

The sketch drawing brings a sign of a descriptive qualitative feature of the design. The element represents a qualitative subject that covers some categories of mode contained in the PPE framework (recognition, comprehension, and association). All result was analyzed based on a group of the respondent, which answering all research question. RQ1: Which reference material mostly referred by a respondent to form a new design of remote control? The RQ2: How the outlook of the design and its rationale? The RQ3: What is the factor they consider the design? The answer is different according to each group of the respondent which is:

\subsubsection{Industrial Design (IDE)}

The answer for RQ2: Figure 3 shows the overall design of form structure having a good balance of aesthetic appearance and ergonomic study emphasizing the holding posture of body form and the shape of the button function. However, the quantity and type of button function remain the same as previous as they are unsure to remove or to categorize it according to priority function. The answer for RQ3: the product architecture from this group very much concerned with the aesthetic value and the ergonomic factor resulted from the sample holding test on the body form.

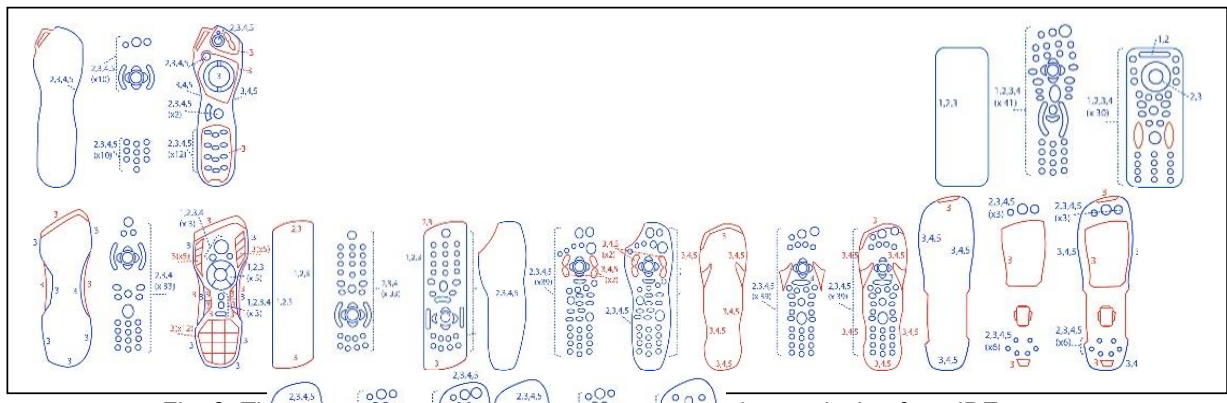

\subsubsection{Engineering Design (ENG)}

\section{The answer for RQ2: Figure 4 shows th}

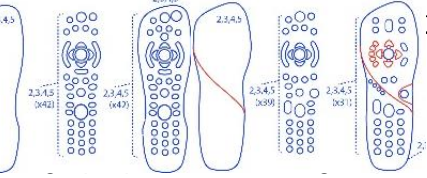

l layout design from IDE group

certain priority button function according to related function besides suggesting the new proportion of body part casing. All the proposed concept is a result of their deep study of elderly related matters (from the internet) before start the sketching work. The proposed design is a different concept from the current one which dares to select or eliminate the new button function according to category and priority function. Anyhow the outlook of design is unbalanced for the aesthetic value compared to button and body form design (as some part took from the internet). The form design based on information gathered from another type of product on the internet. The answer for RQ3: their concern is on product usability, to ease elderly people use the product effectively. 
5.2.3 Interface Desi

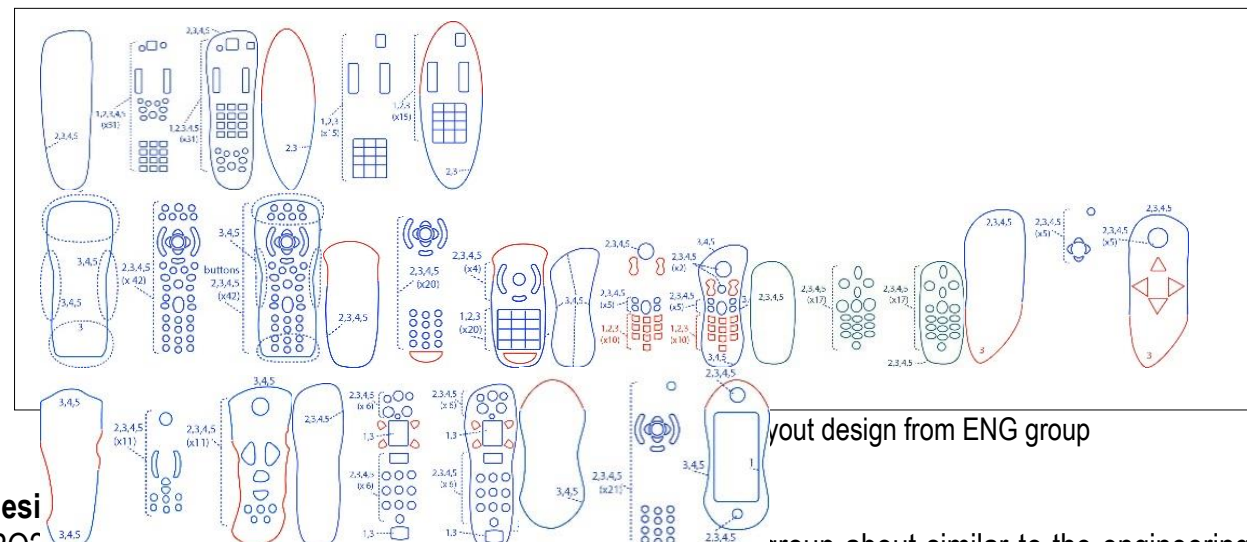

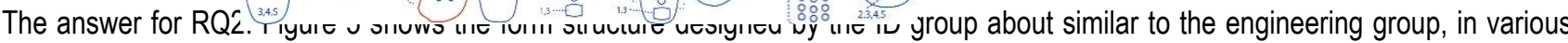
sizes and shape for the body casing part. The respondent from this group capable of deciding and categorizing certain priority functions. The button form and body design considering elderly user weakness, aesthetic value, priority button function and ergonomic (size and grip form). The answer for RQ3: The form design manifest from their testing on remote sample be-sides intensive internet searching.

The general ans 235 (n) influenced by different academic disciplines, knowledge and life experiences. 'The remembering self in the human mind occasionally takes stock of our life experiences and conclude' (Abidin, 2006). The factors related to the design are presented with different quality of usability, aesthetic, ergonomic, button function and new features. However, not all understand the button function and its category besides unclear the issue of elderly limitation. The limitation resulting in some design proposals less concerned with the elderly issue. The overall data finding related to 'insight seeking' is showing a strong connection of three aspects of the form element, the form structure and the interaction with reference material.

\subsection{Conclusion and Recommendations}

Generally, in the design experiment, they performed on the outline form structure only but weak on the content of the button function. In this context, the interaction element is on intuitive perception related to mental image reaction. In principle, to this empirical to analyze the eye interaction with reference materials, play an important role in intuitive form structure which is strongly influencing the forming process. At the abstract level, most of the student is 'excited to design' once studying the panel and testing the Astro TV remote control sample. However, at the semi-concrete and the concrete level, they are struggling to choose and arrange all buttons according to the priority function and the ergonomic factors, even though the information is available at panel 4 and from the website search. This result was confirming our Hypothesis that the amount of knowledge and experience determines the quality of the design solution of the respondent. Through this finding can be used as a fundamental reference on the new product development process, which required a critical concern on design thinking character from three different knowledge domains, as design organization involved different knowledge domain to develop a particular product.

\section{Acknowledgement}

We would like to acknowledge the appreciation of the division of Human Resource Development Fund (HRDF), Multimedia University (MMU) for the financial support to perform this research and participation of the conference. 


\section{References}

Abidin.S.Z., Sigurjonsson, J., Liem, A., \& Keitsch, M. (2008). On the Role of Formgiving in Design. 10th International Conference on Engineering and Product Design Education.

Anwar, R. (2016). Characterizing a syntactic pattern of formgiving in design thinking process. Ph.D. Thesis. Shah Alam: Universiti Teknologi MARA.

Anwar, R., Abidin, S. Z., \& Hassan, O. H. (2016). In-vitro design protocol: Artificial situation strategy uses to comprehend designers' thought. In EDP Sciences: MATEC Web of Conferences, Vol. 52.

Anwar, R., Abidin, S. Z., \& Hassan, O. H. (2015a). Understanding methodological solution in design situation of novice designer. In International Conference on Interactive Collaborative Learning (ICL) (pp. 593-597). Florence: IEEE.

Anwar, R., Hassan, O. H., \& Abidin, S. Z. (2015b). A pattern in formgiving design: Giving priority to a principle solution in industrial design situation. In Gen, M., Kim, K. J., Huang, X., \& Hiroshi, Y. (Eds.). Industrial engineering, management science and applications 2015. Berlin: Springer.

Anwar, R., Abidin, S. Z., \& Hassan, O. H. (2015c). A practical guideline to quantifying qualitative analyses of design cognition. The Turkish Online Journal of Educational Technology. Special Issue 1 for IETC 2015, pp. 13-21.

Akatsu, H., and Miki, H. (2004). Usability Research for the Elderly People. (Oki Technical Review).

Brown, S. L., \& Eisenhardt, K. M. (1995). Product Development: Past Research, Present Findings, and Future Directions. Academy of Management Review 20 (2): 343-378.

Cagan, J., \& Vogel, C. M. (2002). Creating breakthrough products: Innovation from product planning to program approval. Upper Saddle River, NJ: Prentice Hall.

Cova, B., \& Svanfeldt, C. (1993). Societal Innovations and the Postmodern Aestheticization of Everyday Life. International Journal of Research in Marketing 10(3): 297310 .

Fukuda, R. (2009). Usability analysis of home electrical appliances based on eye tracking and physiological data. 'High-Tech Research Center', Project for Private Universities' MEXT Japan.

Gharib, I. (2013). Integration of sketch-based ideation and 3D modeling with CAD systems (Doctoral dissertation, Brunel University School of Engineering and Design Ph.D. Theses).

Hubka, V., \& Eder, W.E. (1982). Principles of Engineering Design. London: Butterworths.

Kumar,V., \& Whitney, P. (2007). Daily life, not markets: customer-centered design. Journal of Business Strategy Vol.28 No.4

McKim, R. H. (1980). Experiences in Visual Thinking (2nd. edition.). Boston: PWS Publishing Company.

Monö, R. (1997). Design for Product Understanding: The Aesthetics of Design from a Semiotic Approach. Stockholm: Liber AB.

Pahl, G., \& Beitz, W. (1996). Engineering Design: A Systematic Approach. London: Springer -Verlag.

Prahalad, C. K., \& Ramaswamy, V. (2000). Co-opting Customer Competence. Harvard Business Review. January-February, 79-87.

Roscoe, J. T. (1975). Fundamental research statistics for the behavioral sciences (2nd Ed.). New York: Holt, Rinehart and Winston.

Schön, D. A. (1983). The reflective practitioner: How professionals think in action (Vol. 5126). Basic books.

Siran Z., Abidin S.Z., Anwar R. (2018) Design Elements: The Interaction of Elderly People on Product Interfaces. In: Anwar R., Mahamood M., Md. Zain D., Abd Aziz M., Hassan O., Abidin S. (eds) Proceedings of the Art and Design International Conference (AnDIC 2016). Springer, Singapore

Warell, A. (2001). Design syntactic: A functional approach to visual product form. Chalmers University of Technology, Gothenburg.

Warell, A. (2008). Modelling Perceptual Product Experience - Towards a Cohesive Framework of Presentation and Representation in Design. In Design \& Emotion 2008; Proceedings of the $6^{\text {th }}$ International Conference on Design \& Emotion, October 6-9. Hong Kong: Hong Kong Polytechnic University. 